\title{
Using Guasha to treat musculoskeletal pain: A systematic review of controlled clinical trials
}

\author{
Myeong Soo Lee*, Tae-Young Choi, Jong-In Kim, Sun-Mi Choi
}

\begin{abstract}
Background: Guasha is a therapeutic method for pain management using tools to scrape or rub the surface of the body to relieve blood stagnation. This study aims to systematically review the controlled clinical trials on the effectiveness of using Guasha to treat musculoskeletal pain.

Methods: We searched 11 databases (without language restrictions): MEDLINE, Allied and Complementary Medicine (AMED), EMBASE, Cumulative Index to Nursing and Allied Health Literature (CINAHL), Korean Studies Information (KSI), DBPIA, Korea Institute of Science and Technology Information (KISTI), KoreaMed, Research Information Service System (RISS), China National Knowledge Infrastructure (CNKI) and the Cochrane Library. The search strategy was Guasha (OR scraping) AND pain. Risk of bias was assessed with the Cochrane criteria (i.e. sequence generation, blinding, incomplete outcome measures and allocation concealment).

Results: Five randomized controlled trials (RCTs) and two controlled clinical trials (CCTs) were included in the present study. Two RCTs compared Guasha with acupuncture in terms of effectiveness, while the other trials compared Guasha with no treatment (1 trial), acupuncture (4 trials), herbal injection (1 trial) and massage or electric current therapy (1 trial). While two RCTs suggested favorable effects of Guasha on pain reduction and response rate, the quality of these RCTs was poor. One CCT reported beneficial effects of Guasha on musculoskeletal pain but had low methodological quality.
\end{abstract}

Conclusion: Current evidence is insufficient to show that Guasha is effective in pain management. Further RCTs are warranted and methodological quality should be improved.

\section{Background}

Guasha was defined as a therapeutic modality that uses several tools to scrape or rub the surface of the body to relieve blood (Xue) stagnation. Guasha is used for pain relief in Chinese medicine. Tools for Guasha including a Chinese soup spoon, an edge-worn coin, a slice of water-buffalo horn, a cow rib, honed jade and a simple metal cap with a smooth round lip with oil or water are used in Guasha to scrape or rub the skin to relieve blood stagnation at the body surface [1]. Guasha is also used to treat common cold, flu, respiratory problems and musculoskeletal (MS) pain [2].

There are three possible mechanisms of using Guasha to relieve MS pain: (1) Guasha increases local microcirculation thereby decreasing distal myalgia [1]; (2) pain is

\footnotetext{
* Correspondence: mslee@kiom.re.kr

Acupuncture, Moxibustion and Meridian Research Center, Division of Standard Research, Korea Institute of Oriental Medicine, Daejeon 305-811,
} South Korea reduced through stimulating the serotonergic, noradrenergic and opioid systems; (3) Guasha minimizes the direct effects of pain at nociceptors, their surroundings and the interconnections within the spinal cord [3]. However, none of these theories can be established before actual effectiveness of Guasha is demonstrated.

To date, no systematic review is available to evaluate the effectiveness of using Guasha to treat MS pain. The present systematic review aims to critically evaluate the results of controlled clinical trials on the effectiveness of using Guasha to treat MS pain.

\section{Methods}

Data sources

The following databases were searched between their inception and July 2009: MEDLINE (1969), Allied and Complementary Medicine (AMED) (1995), EMBASE (1966), Cumulative Index to Nursing and Allied Health Literature (CINAHL) (1981), Korean Studies Information 
(KSI) (1966), DBPIA (1966), Korea Institute of Science and Technology Information (KISTI) (1959), KoreaMed (1959), Research Information Service System (RISS) (1959), China National Knowledge Infrastructure (CNKI) (1974) and the Cochrane Library (Issue 3, 2009). The search strategy was Guasha (OR scraping) AND pain. Korean and Chinese terms for Guasha AND pain were used when searching the Korean and Chinese databases. We also searched in the journals Focus on Alternative and Complementary Therapies (FACT) and Research in Complementary Medicine (Forschende Komplementarmedizin) electronically published between 1994 and July 2009. In addition, the references in all retrieved articles as well as our department files were searched.

\section{Study selection}

We included all controlled clinical trials on using Guasha to treat patients (regardless gender or age) diagnosed with MS pain. Trials published as journal articles, dissertations and abstracts were eligible. We excluded the trials that compared one type of Guasha with another. Trials with Guasha as a part of a complex intervention were also excluded. No language restrictions were imposed.

\section{Data extraction and quality assessment}

Hard copies of all articles included in the study were read in full independently by two authors (TYC, JIK). Data from the articles were validated and extracted according to pre-defined criteria (Table 1).

The Cochrane classification with four criteria (i.e. sequence generation, blinding, incomplete outcome measures and allocation concealment) was used to assess the risk of bias [4]. As it is difficult to blind Guasha therapists, we assessed the blinding of patient and assessor separately. A point was given for assessor blinding if pain was assessed by another person (who was unaware of the group assignment). Disagreements were resolved between the two authors (TYC, JIK) through discussion and, if necessary, consulting another author (MSL).

\section{Data synthesis}

Chi-square test was used to compare the response rates. The relative risk (RR), mean difference and 95\% confidence intervals (95\%CIs) from each study were estimated with Review Manager (RevMan) Version 5.0 for Windows (Nordic Cochrane Center, Denmark).

\section{Results \\ Study description}

The literature search found 224 articles, of which 217 were excluded after the full texts were retrieved (Figure 1 ). A total of 151 studies were excluded because they did not have control $(n=44)$ or they were part of a complex treatment or concomitant use of other therapies $(n=89)$. Five randomized controlled trials (RCTs) [5-9] and two controlled clinical trials (CCTs) [10,11] fulfilled the inclusion criteria (Table 1). All included studies were conducted in China, including treatment for fibromyalgia (1 trial) [5], neck stiffness (1 trial) [6], cervical spondylosis (3 trials) $[7,8,10]$, scapulohumeral periarthritis (1 trial) [9] and lumbar disc herniation (1 trial) [11]. These studies were divided into four categories: (1) recovery, (2) marked improvement, (3) improvement and (4) no change. The sample sizes ranged between 60 and 240 .

\section{Assessment of risk of bias}

All of the included studies (five RCTs and two CCTs) had risks of performance bias, attrition bias and detection bias. None of these studies reported randomization methods or allocation concealment or the blinding of the outcome assessors. Dropouts and withdrawals were not mentioned in these studies.

\section{Outcomes}

One RCT comparing Guasha with acupuncture reported significantly favorable effects of Guasha on pain and the number of pain points in fibromyalgia patients [5]. Another RCT comparing Guasha with massage and electric current therapy did not show beneficial effects of Guasha in patients with neck stiffness [6]. Two other RCTs comparing Guasha with herbal injection in patients with cervical spondylosis [7] or no treatment did not show favorable effects of Guasha [8]. The last RCT comparing Guasha with acupuncture in patients with scapulohumeral periarthritis reported that Guasha was superior in recovery rate [9].

One CCT comparing effects of Guasha in patients with cervical spondylosis with acupuncture found favorable effects of Guasha on the recovery rate in patients [10]. Another CCT comparing effects of Guasha in patients with lumbar disc herniation with acupuncture plus moxibustion did not find favorable effects of Guasha [11].

In all seven studies, no adverse events were reported.

\section{Discussion}

Low-quality trials are more likely to overestimate effect sizes [12]. In the case of Guasha, few rigorous trials have tested the effects of Guasha on MS pain and evidence from the included studiesis limited. In terms of sequence generation, blinding, incomplete outcome measures and allocation concealment, all of the included studies had a high risk of biases. None of the studies reported allocation concealment.

Guasha was compared with massage or electric current therapy [6], herbal injection [7], no treatment [8] or acupuncture [5,9-11]. While beneficial effects of Guasha compared to acupuncture were found in two trials $[5,9]$, such trials comparing the effects of Guasha with another unproved treatment are not informative. One RCT failed to show that Guasha is better than massage or electric current therapy. The other RCT failed to 
Table 1 Summary of controlled clinical studies of Guasha for musculoskeletal pain conditions

\begin{tabular}{|c|c|c|c|c|}
\hline $\begin{array}{l}\text { First author } \\
\text { (year) }\end{array}$ & $\begin{array}{l}\text { Design/sample } \\
\text { size } \\
\text { Conditions }\end{array}$ & Intervention group (regime) & $\begin{array}{l}\text { Main } \\
\text { outcomes }\end{array}$ & Results \\
\hline $\begin{array}{l}\text { Tang (2008) } \\
{[5]}\end{array}$ & $\begin{array}{l}\text { RCT } 120 \\
\text { Fibromyalgia } \\
\text { syndrome }\end{array}$ & $\begin{array}{l}\text { (A) Guasha ( } n \text {.r., once per } 3 \text { days, } 5 \text { times total, } n=60 \text { ) } \\
\text { (B) AT ( } 30 \text { min, once daily, } 15 \text { times, } n=60 \text { ) }\end{array}$ & $\begin{array}{l}\text { 1) VAS (100 } \\
\text { mm) } \\
\text { 2) Number of } \\
\text { pain points } \\
\text { 3) Response rate }\end{array}$ & $\begin{array}{l}\text { 1) } M D,-9.5,95 \% \text { Cls }(-14.5 \text { to }-4.5) P \\
<0.0002 \text { in favor of } A \\
\text { 2) } M D,-5.0,95 \% \text { Cls }(-6.5 \text { to }-3.5), P \\
<0.0001 \text { in favor of } A \\
\text { 3) (A) } 29 / 16 / 10 / 8 \text {; (B) } 10 / 8 / 12 / 20 \\
\text { Improved } \\
\text { 1.3 }[0.94,1.13], P=0.01 \\
\text { Recovery } \\
2.9[1.55,5.41], P=0.0008\end{array}$ \\
\hline $\begin{array}{l}\text { Chen (1995) } \\
{[6]}\end{array}$ & $\begin{array}{l}\text { RCT/90 } \\
\text { Neck stiffness }\end{array}$ & $\begin{array}{l}\text { (A) Guasha (20 min, once per } 3 \sim 7 \text { days, } n . r ., n=30) \\
\text { (B) Massage }(10 \mathrm{~min}, \mathrm{n}=30 \text { ) } \\
\text { (C) Electric current therapy }(10 \mathrm{~min}, \mathrm{n}=30)\end{array}$ & Response rate & $\begin{array}{l}\text { (A) } 27 / 1 / 2 / 0 ; \text { (B) } 27 / 2 / 1 / 0 \\
\text { (C) } 28 / 1 / 1 / 0 \\
\text { NS } \\
\text { NS }\end{array}$ \\
\hline Ma (2003) [7] & $\begin{array}{l}\mathrm{RCT} / 50 \\
\text { Cervical } \\
\text { spondylosis }\end{array}$ & $\begin{array}{l}\text { (A) Guasha ( } 1 \text { session }=\text { n.r., once per } 2 \text { days, total } 10 \\
\text { times, } n=15 \text { ) } \\
\text { (B) Herbal injection (once daily, total } 20 \text { times, } \\
n=35 \text { ) }\end{array}$ & Response rate & $\begin{array}{l}\text { (A) } 0 / 7 / 6 / 2 \text {; (B) } 0 / 25 / 7 / 1 \\
\text { Improved } \\
0.92[0.74,1.14], \text { NS } \\
\text { Recovery } \\
\text { N/A }\end{array}$ \\
\hline Wu (1996) [8] & $\begin{array}{l}\mathrm{RCT} / 100 \\
\text { Cervical } \\
\text { spondylosis }\end{array}$ & $\begin{array}{l}\text { (A) Guasha ( } \mathrm{n} . \mathrm{r} . \text {, once per } 2 \text { days, total } 10 \text { times, } \mathrm{n}= \\
\text { 72) } \\
\text { (B) No treatment }(\mathrm{n}=28)\end{array}$ & Response rate & $\begin{array}{l}\text { (A) } 39 / 0 / 28 / 5 ; \text { (B) } 14 / 0 / 8 / 6 \\
\text { Improved } \\
1.18[0.97,1.45], \mathrm{NS}^{\dagger} \\
\text { Recovery } \\
1.08[0.71,1.66], \mathrm{NS}\end{array}$ \\
\hline Li (1996) [9] & $\begin{array}{l}\mathrm{RCT} / 60 \\
\text { Scapulohumeral } \\
\text { periarthritis }\end{array}$ & $\begin{array}{l}\text { (A) Guasha (n.r., once per } 4 \sim 5 \text { days, total } 5 \text { times, } n= \\
\text { 30) } \\
\text { (B) AT ( } 20 \text { min, once daily, total } 10 \text { times, } n=30 \text { ) }\end{array}$ & Response rate & $\begin{array}{l}\text { (A) 18/8/4/0; (B) 10/10/8/2 } \\
\text { Improved } \\
1.07[0.96,1.20], \mathrm{NS}^{\dagger} \\
\text { Recovery } \\
1.8[1.00,3.25], \mathrm{P}=0.05\end{array}$ \\
\hline $\begin{array}{l}\text { Guo (1995) } \\
{[10]}\end{array}$ & $\begin{array}{l}\mathrm{CCT} / 76 \\
\text { Cervical } \\
\text { spondylosis }\end{array}$ & $\begin{array}{l}\text { (A) Guasha }(1 \text { session }=20 \text { min, once per } 3 \text { days, total } \\
10 \text { times, } 2 \text { session, } n=38 \text { ) } \\
\text { (B) AT ( } 1 \text { session }=30 \text { min, once per } 2 \text { days, total } 10 \\
\text { times, } 2 \text { session, } n=38 \text { ) }\end{array}$ & Response rate & $\begin{array}{l}\text { (A) } 29 / 6 / 2 / 1 ;(B) 19 / 7 / 9 / 3 \\
\text { Improved } \\
1.06[0.95,1.18], \mathrm{NS}^{+} \\
\text {Recovery } \\
1.53[1.06,2.20], \mathrm{P}=0.02\end{array}$ \\
\hline $\begin{array}{l}\text { Wang (2004) } \\
{[11]}\end{array}$ & $\begin{array}{l}\text { CCT/240 } \\
\text { Lumbar disc } \\
\text { herniation }\end{array}$ & $\begin{array}{l}\text { (A) Guasha }(1 \text { session }=n . r . \text { once per } 7 \text { days, total } 3 \\
\text { times, } 3 \text { session, } n=160) \\
\text { (B) AT plus moxa }(n=80)\end{array}$ & Response rate & $\begin{array}{l}\text { (A) } 32 / 69 / 45 / 14 ;(B) 11 / 27 / 33 / 9 \\
\text { Improved } \\
1.03[0.94,1.13], \mathrm{NS}^{\dagger} \\
\text { Recovery } \\
1.45[0.77,2.73], \mathrm{NS}\end{array}$ \\
\hline
\end{tabular}

n.r.: not reported; NS: no significance; AT: acupuncture; RCT: randomized controlled trial; CCT: controlled clinical trial; VAS: visual analog scale

Response rate was divided to four categories: (1) recovery, (2) marked improvement, (3) improvement and (4) no change

${ }^{+}$We re-calculated the significance with RevMan for two categories: improved cases and recovery cases of each group.

The original authors reported a statistical significance for these studies $(P<0.05)$.

show favorable effects of Guasha when compared to no treatment in patients with cervical spondylosis [8]. This may suggest that the effects of Guasha are non-specific. Controlled trials indicated that Guasha reduced MS pain in cervical spondylosis patients but not in patients with lumbar disc herniation $[10,11]$. All of the included trials failed to report details of statistical analysis; thus, it is difficult to interpret the results. Although three studies reported favorable effects of Guasha [8,10,11], our re-analysis failed to show the claimed effectiveness in pain relief (Table 1).

Our review has a number of important limitations. Although strong efforts were made to retrieve all controlled clinical trials on the subject, we are not absolutely certain that we succeeded in doing so. Biases in publishing and reporting are possible [13,14]. It is also possible that negative RCTs remain unpublished and thus the overall picture may be even less positive.

Future RCTs of Guasha on pain management should adhere to accepted standards of trial methodology and consider combined use of Guasha and other therapies. Sufficient sample sizes, validated outcome measures and an adequate placebo procedure for Guasha are necessary in further research.

\section{Conclusion}

Current evidence is insufficient to show that Guasha is effective in pain management. Further RCTs are warranted and methodological quality should be improved. 


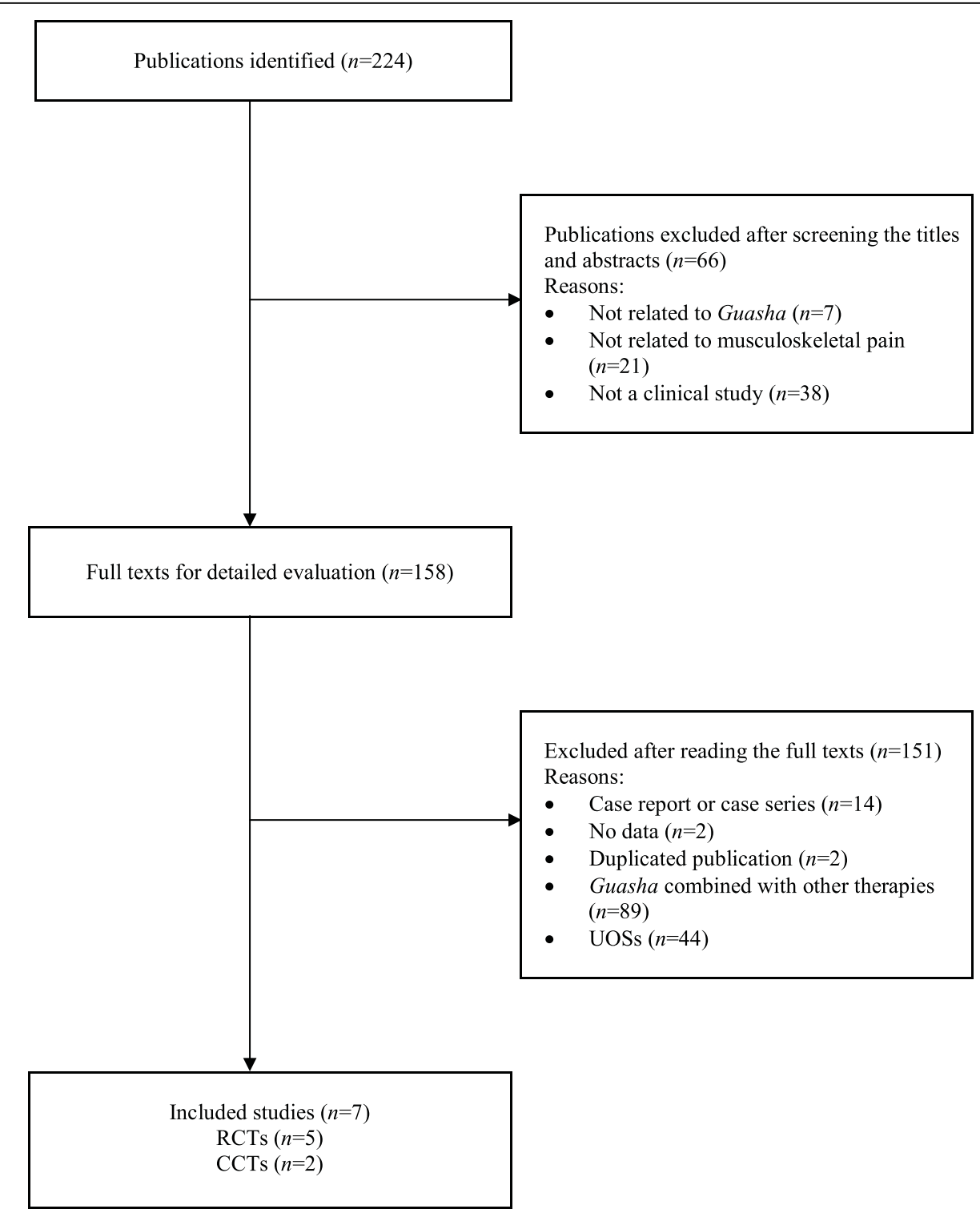

Figure 1 Flowchart of the selection process for the trials. RCT: randomized controlled trial. CCT: controlled clinical trial. UOS: uncontrolled observational study.

\section{Acknowledgements}

This research has been supported by the Korea Institute of Oriental Medicine (K09050).

\section{Authors' contributions}

MSL and JIK conceived the study design. MSL, TYC and JIK searched and selected the trials, extracted, analyzed and interpreted the data. MSL and TYC drafted the manuscript. SMC helped with the study design and critically reviewed the manuscript. All authors read and approved the final version of the manuscript.

\section{Competing interests}

The authors declare that they have no competing interests.

Received: 7 November 2009

Accepted: 29 January 2010 Published: 29 January 2010

\section{References}

1. Nielsen A, Knoblauch NT, Dobos GJ, Michalsen A, Kaptchuk TJ: The effect of Guasha treatment on the microcirculation of surface tissue: a pilot study in healthy subjects. Explore (NY) 2007, 3:456-466.

2. Nielsen A: Guasha research and the language of integrative medicine. J Bodyw Mov Ther 2009, 13:63-72.

3. Musial F, Michalsen A, Dobos G: Functional chronic pain syndromes and naturopathic treatments: neurobiological foundations. Forsch Komplementmed 2008, 15:97-103.

4. Higgins JPT, Altman DG: Assessing Risk of Bias in Included Studies. Cochrane Handbook for Systematic Reviews of Interventions West Sussex, England: Wiley-BlackwellJulian PTH, Green S 2008, 187-241.

5. Tang SM, Liu EL, Llu ZW: Clinical observation scraping therapy for treats fibromyalgia syndrome. Sichuan Zhongyi 2008, 26:108-109.

6. Chen KM, Chen WB: A clinical observation of GuaSha treatment for neck stiffiness. Zhongguo Minjian Liaofa 1995, 17-18. 
7. Ma H, Li SZ, Zheng HM: Clinical observation gua sha plus herbal injection with 83 cases of cervical spondylosis. Zhengjiu Lingchuang Zazhi 2003, 19:27-28.

8. Wu FL: Guasha treatment for cervical spondylosis of 72 cases. Shanghai Zhengjiu Zazhi 1996, 15:205-206.

9. Li J, Li GZ: Guasha treatment for scapulohumeral periarthritis of 30 cases. Shanghai Zhengjiu Zazhi 1996, 15:240.

10. Gou X: Clinical observation of 38 cases of cervical spondylosis treated by Guasha. Zhongyi Waizhi Zazhi 1995, 2:40.

11. Wang ZG, Tao Y, Wu NT: The effect of coin scraping therapy for the treatment of lumbar disc herniation. Zhongguo Zhongyi Gushangke Zazhi 2004, 12:7-10.

12. Moore A, McQuay H: Bandolier's Little Book of Making Sense of the Medical Evidence Oxford, UK: Oxford University Press 2006.

13. Egger M, Smith GD: Bias in location and selection of studies. BMJ 1998, 316:61-66.

14. Ernst E, Pittler MH: Alternative therapy bias. Nature 1997, 385:480.

doi:10.1186/1749-8546-5-5

Cite this article as: Lee et al.: Using Guasha to treat musculoskeletal pain:

A systematic review of controlled clinical trials. Chinese Medicine 2010 5:5.

Publish with Biomed Central and every scientist can read your work free of charge

"BioMed Central will be the most significant development for disseminating the results of biomedical research in our lifetime. "

Sir Paul Nurse, Cancer Research UK

Your research papers will be:

- available free of charge to the entire biomedical community

- peer reviewed and published immediately upon acceptance

- cited in PubMed and archived on PubMed Central

- yours - you keep the copyright 